\title{
Development Trend of Small Island District in Tropical Monsoon Region (Case Study: Ly Son and Phu Quy Island Districts, Vietnam)
}

\author{
Hang Anh Nguyen ${ }^{1}$, Thi Thanh Hang Phan ${ }^{2}$ \\ ${ }^{1}$ FPT Software, Hanoi, Vietnam \\ ${ }^{2}$ Department of Surface Water Resources, Institute of Geography, Vietnam Academy of Science and Technology, Hanoi, Vietnam \\ Email: Hanganhnguyen190@gmail.com, Hangphanvn@yahoo.com
}

How to cite this paper: Nguyen, H. A., \& Phan, T. T. H. (2020). Development Trend of Small Island District in Tropical Monsoon Region (Case Study: Ly Son and Phu Quy Island Districts, Vietnam). Journal of Geoscience and Environment Protection, 8, 105-124.

https://doi.org/10.4236/gep.2020.84008

Received: March 26, 2020

Accepted: April 23, 2020

Published: April 26, 2020

Copyright $\odot 2020$ by author(s) and Scientific Research Publishing Inc. This work is licensed under the Creative Commons Attribution International License (CC BY 4.0).

http://creativecommons.org/licenses/by/4.0/

\begin{abstract}
Ly Son (Quang Ngai province) and Phu Quy (Binh Thuan province) are two island districts in Vietnam that have similar natural characteristics; both are facing the issues of sustainable economic development. This research applied Man-Kendall model to estimate the trend of some socio-economic elements in these two island districts that have been collected during the period of 2002-2018. In general, socio-economic factors showed a tendency to increase recently. Ly Son island district has faster growth rate than that of Phu Quy because Phu Quy is farther from the mainland, more difficult to access and this island district does not own distinct local products. However, with the current development speed, Ly Son is facing several consequences such as insufficient water sources to meet the water demand and security instability due to the increasing number of visitors to the island. This research also proposed that, in order to sustainably develop the two island districts, there should be a specific structure for economic development orientation among sectors based on phased schedule. More importantly, tourism development planning should take capacity into consideration. Fishing practices should pay attention to methods and fishing equipment. Infrastructure investment for environmental protection as well as advocacy program to minimize the use of plastic bags should be done on a regular basis.
\end{abstract}

\section{Keywords}

Sustainable Development, Small Island Districts and Tropical Monsoon Region

\section{Introduction}

Sustainable development has become a global concern. In the world development process, each region as well as each country is facing pressing issues that have 
both shared and local characteristics; one of which is the economic development that normally associates with the exploitation of non-renewable resources, the damage of the natural environment and the breaking of the ecological balance, resulting in catastrophic disasters. Vietnam is a tropical monsoon country that has about 4000 islands with an area of about $1600 \mathrm{~km}^{2}$, only 100 of which have an area of $1 \mathrm{~km}^{2}$ or more. In recent years, despite the great progress in marine economy, there also exist consequences such as the pressure of population growth on the islands, the restructuring of the island's economy and the redistribution of the labor force. The islands are also deeply affected by climate change, sea-level rise, extreme weather events, coastal erosion and coral bleaching which exploited the island's resources such as reducing fish production, reducing the value of the tourism destination...

In the study of "Ecology and Economics in Small Islands: Constructing a Framework for Sustainable Development” (Bass, 1993), the pressure of socio-economic development on small islands with limited resources, dependent economy, exposure to many natural disasters, and vulnerable ecosystems was considered. Some islands also have high population densities. Based on the research results, the author has proposed a framework convention for the sustainable development of small islands. In 2014, the United Nations issued "Trends in Sustainable Development. Small Island Developing States" (SIDS, 2014) and highlighted the SIDS vulnerabilities and recent trends in sustainable development. The research of "Addressing the threats to tourism sustainability using systems thinking" (Mai \& Smith, 2015) which studied Cat Ba Island, Vietnam, described the link between tourism development and the theory system. This link was used to identify the basic system structures that are likely to affect tourism development and sustainable development on Cat Ba Island, Vietnam. In the study of 2016, Isabel Banos-González et al.' proposed a sustainable assessment tool for sustainable social-ecosystems of El Hierro and Fuerteventura Islands, Canary Islands, Spain (Banos-Gonzalez et al., 2016). In 2018, John Connell in his publication, "Islands: balancing development and sustainability?" (John Connell, 2018) observed the sustainable development of the islands. In fact, small islands often suffer from great environmental pressures as well as economic challenges due to their small sizes and geographic isolations, specific biodiversity, frequent exposure to natural disasters, high density of population and low local resources base. Until now, there has been no study on sustainable development trends for small islands in the tropical monsoon region. In this study, the development trend of small island districts (case study: Ly Son and Phu Quy) in the tropical monsoon region is considered.

\section{Study Area}

Ly Son (Quang Ngai province) and Phu Quy (Binh Thuan province) are 2 island districts in the central marine region of Vietnam. The positions of two island districts are showed in Figure 1. Ly Son island district has an area of $9.97 \mathrm{~km}^{2}$ 
(Figure 2) with the inclusion of 3 communes An Hai, An Vinh and An Binh. Among the population of approximately 22,000 people, about $60 \%$ of households works in sea fishing, 30\% of households works in agriculture (mainly growing onions, garlic and corn) and $10 \%$ of households works in other sectors such as trading or services. Ly Son island district has 5 erupted volcanoes, including Thoi Loi, Gieng Tien, Hon Vung, Hon Soi and Hon Tai, all of which were formed due to the eruption of volcanic lava 25 - 30 million years ago. Volcanic terrain which accounts for $70 \%$ of the island's area has created beautiful landscapes with cliffs and stone roofs, caves as well as rocky beaches that contain many mysterious and fascinating legends.

The annual average temperature of the island district is $26.6^{\circ} \mathrm{C}$; monthly differences were not considerable. The highest monthly average temperature is about $29.5^{\circ} \mathrm{C}$ (in May, July, and August) while the lowest monthly average is $23.0^{\circ} \mathrm{C}$ (in January). The highest temperature observed at Ly Son station was $36.8^{\circ} \mathrm{C}$ while the lowest was $15.4^{\circ} \mathrm{C}$ (Phan Thi Thanh Hang et al., 2016a). The annual average seawater salinity is $30 \%$ - $31 \%$; the highest was $34 \%$. Ly Son has a rainfall of 2279 mm/year (Phan Thi Thanh Hang et al., 2016a). There are neither rivers nor streams on Ly Son island and temporary flow only appeared in the rainy season.

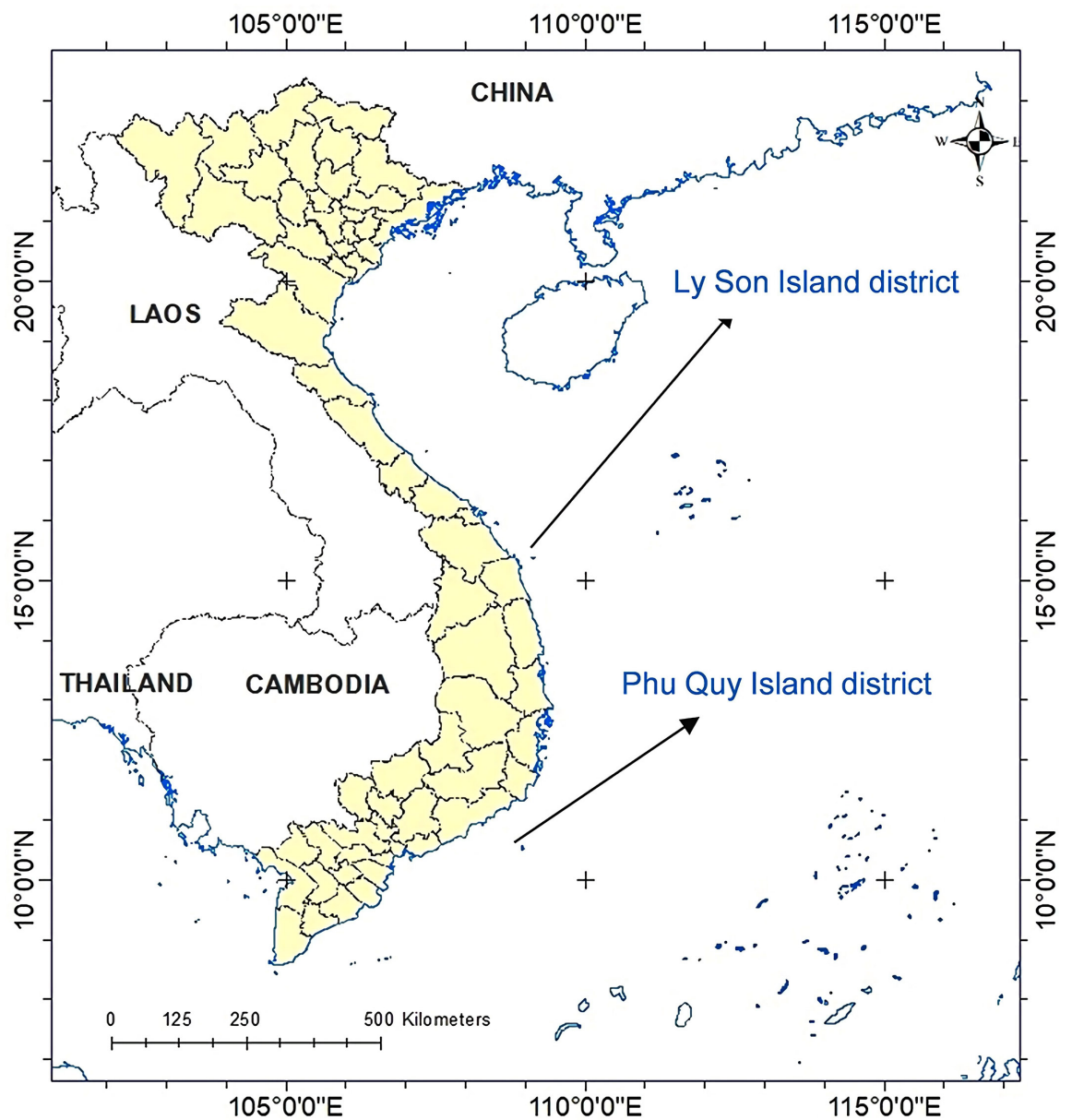

Figure 1. Positions of Ly Son and Phu Quy island districts. 


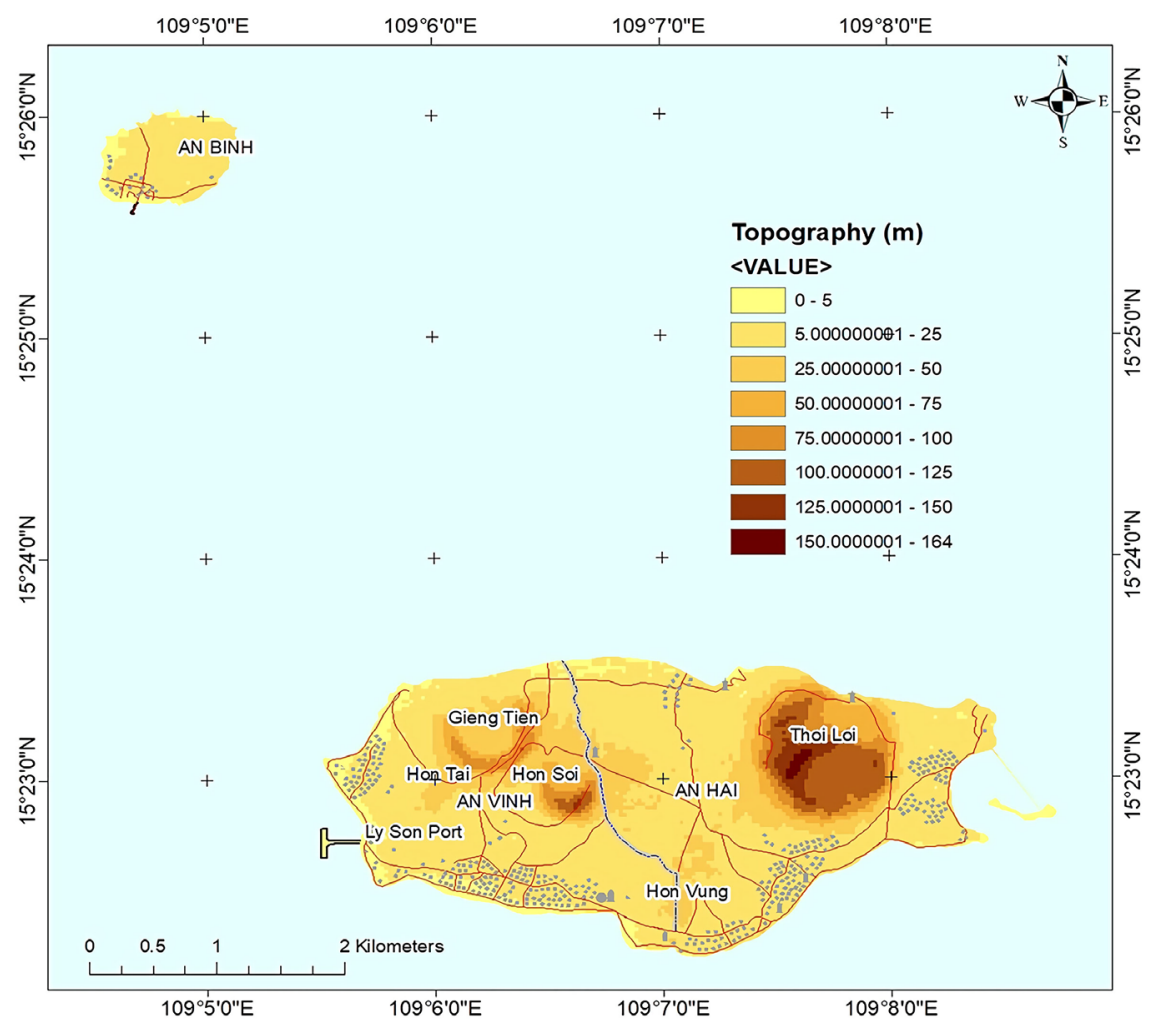

Figure 2. Map of Ly Son island district.

Water sources that are being used for living and economic activities on the island based solely on underground water. However, the island is lack of water resources, especially in the dry season. Therefore, without water resources, the socio-economic development will cope with unsustainability.

Biological resources in Ly Son area are quite abundant, including coral reefs, mollusks with conch shells, abalone, pearl, oysters, clams. Crustacean resources include lobster, white sea cucumber, sea cucumber, etc. However, in recent years, coral reefs in Ly Son waters have shown signs of disadvantage due to fishing and the exploitation of sand as well as corals to grow garlic.

Phu Quy is an island district of about $16 \mathrm{~km}^{2}$ that belongs to Binh Thuan Province (Figure 3) with 3 communes Long Hai, Ngu Phung and Tam Thanh. Phu Quy is $120 \mathrm{~km}$ southeast of Phan Thiet city. Phu Quy Island is in the largest fish reserve of Vietnam. With a total population of nearly 28,000 people, the population density is about 10 times the average density of Binh Thuan Province. The island district has neither surface water system nor irrigation network which led to the fact that groundwater is being used for almost all purposes. Nevertheless, the use of groundwater on the island is inadequate due to the high amount of evaporation, which is approximately equal to the total rainfall. Moreover, groundwater reserves are mainly being concentrated in aquifers with local pressure. For instance, sand containing gravel and pebbles originating from early-middle Pleistocene are being distributed mainly in coastal areas of Tam Thanh, Ngu Phung and Long Hai communes. Therefore, water resources pose a problem in planning as well as in promoting sustainable socio-economic development of the island. 


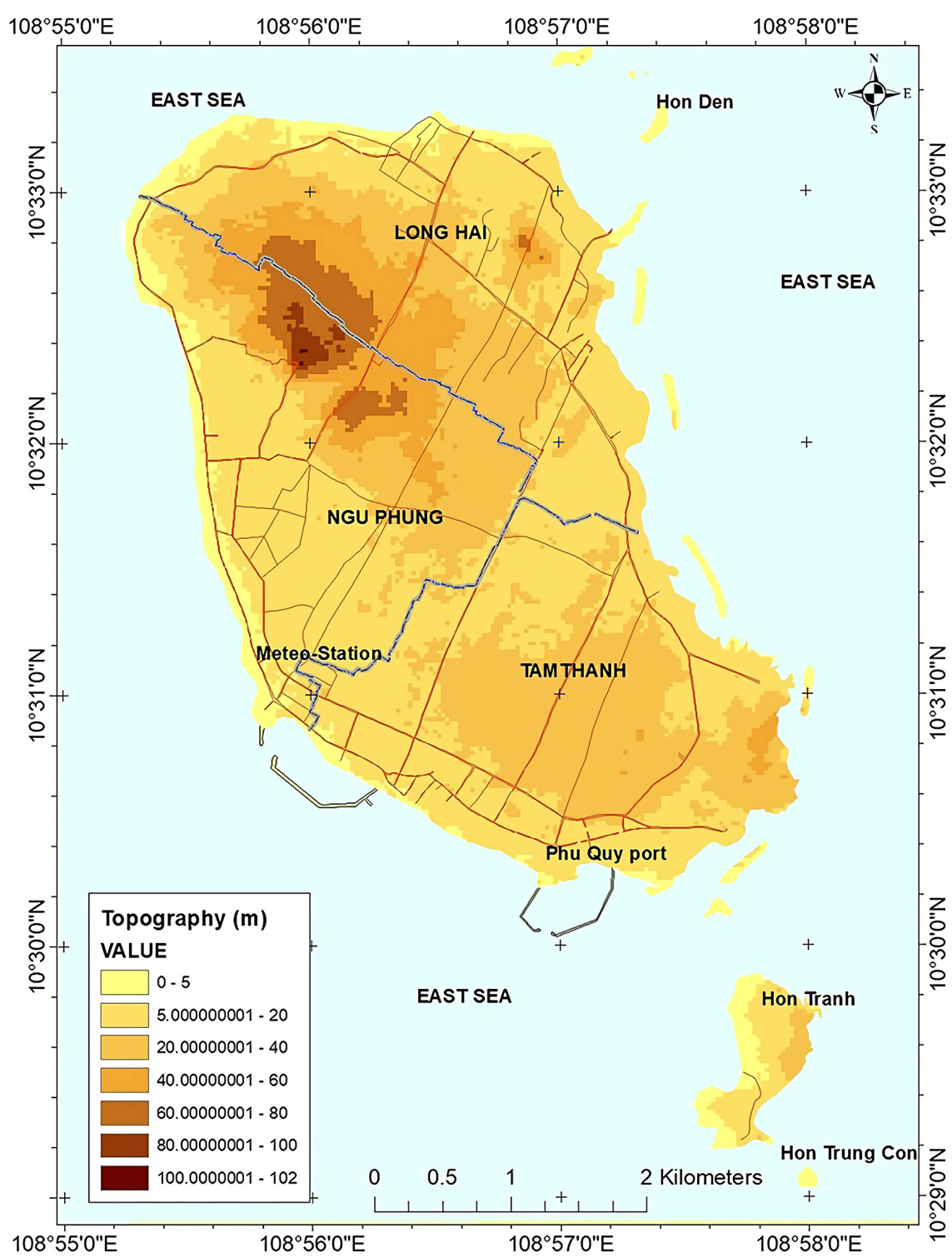

Figure 3. Map of Phu Quy island district.

The average air temperature on the island is $27.3^{\circ} \mathrm{C}$. The rainy season in Phu Quy island is from May to November, with an average annual rainfall of 1305 $\mathrm{mm}$ /year (Phan Thi Thanh Hang et al., 2016b). The average annual evaporation reaches $1260 \mathrm{~mm} /$ year. Air humidity is $83.5 \%$. In recent years, the frequency of storms in the region has increased (Phan Thi Thanh Hang et al., 2016b).

The biodiversity of the sea around Phu Quy island has not been studied in detail. There is a large area of coral in the high seas of Phu Quy island, where Acropora spp and Pocillopora spp are dominant. The western side of the island has a flat reef of $600 \mathrm{~m}$ wide, forming a strip of lagoon that covered with seagrass. In addition, there are Dugong species and seagrass beds in this marine area.

Based on observations and previous studies, it can be said that both island districts of Ly Son and Phu Quy are in the process of developing marine economy. The main economic sectors in the small island districts in the tropical mon- 
soon region are fishing, tourism and agriculture. However, socio-economic development is facing many problems such as the increase in population together with the rise of water demand, unsecured living, the emerge of potential social problems and a high frequency of natural disasters. The asynchronous development and lack of control among economic sectors on the island not only affected the natural environment but also led to social consequences such as unsustainable tourism development which will be the premise of the instability of political security, social safety and social order on the island. The two island districts are also the home of many natural disasters, especially the impacts of climate change that have had a strong impact on the life and conditions on the island. According to the climate change scenario published in 2016 (MONRE, 2016), if the sea level rises by $100 \mathrm{~cm}$, area of many islands will be significantly flooded, which will be 39.3 ha and 145 ha respectively in Ly Son and Phu Quy Island.

\section{Methodology}

The Mann-Kendall test (Kendall, 1975) is a non-parametric test to identify trends in time series data. The test compares relative magnitudes of sample data rather than the data values themselves. One benefit of this test is that the data need not to conform to any distribution. Moreover, data reported as non-detects can be included by assigning them a common value that is smaller than the smallest measured value in the data set. The procedure that will be described in the subsequent paragraphs assumes that there exists only one data value per period. When multiple data points exist for a single period, the median value is used. The data values are evaluated as an ordered time series. Each data value is compared to all subsequent data values. The initial value of the Mann-Kendall statistic, $S$, is assumed to be 0 (i.e., no trend). If a data value from a later period is higher than a data value from an earlier period, $S$ is incremented by 1 . In contrast, if the data value from a later period is lower than a data value sampled earlier, $S$ is decremented by 1 . The net result of all such increments and decrements yields the final value of $S$. Let $x_{1}, x_{2}, \ldots x_{n}$ represent $\mathrm{n}$ data points where $x_{j}$ represents the data point at time $j$. Then the Mann-Kendall statistic $(S)$ is given by

$$
S=\sum_{n-1}^{k-1} \sum_{j-k+1}^{n} \operatorname{sgn}\left(x_{j}-x_{k}\right)
$$

(Pohlert, 2020)

where:

$$
\begin{aligned}
\operatorname{sgn}\left(x_{j}-x_{k}\right) & =1 \text { if } x_{j}-x_{k}>0 \\
& =0 \text { if } x_{j}-x_{k}=0 \\
& =-1 \text { if } x_{j}-x_{k}<0
\end{aligned}
$$

A very high positive value of $S$ is an indicator of an increasing trend, and a very low negative value indicates a decreasing trend. However, it is necessary to compute the probability associated with $S$ and the sample size, $n$, to statistically quantify the significance of the trend. The variance of $S, \operatorname{VAR}(S)$ is calculated by the following equation: 


$$
\operatorname{VAR}(S)=\frac{1}{18}\left[n(n-1)-\sum_{p-1}^{g} t_{p}\left(t_{p}-1\right)\left(2 t_{p}+5\right)\right]
$$

(Pohlert, 2020)

where: $n$ is the number of data points, $g$ is the number of tied groups (a tied group is a set of sample data having the same value), and $t_{p}$ is the number of data points in the $p^{\text {th }}$ group.

A normalized test statistic $Z$ is calculated as follows:

$$
\begin{gathered}
Z=\frac{S-1}{[\operatorname{VAR}(S)]^{1 / 2}} \text { if } S>0 \\
Z=0 \text { if } S>0 \\
Z=\frac{S+1}{[\operatorname{VAR}(S)]^{1 / 2}} \text { if } S<0
\end{gathered}
$$

(Pohlert, 2020)

Then, the computation of the probability associated with this normalized test statistic is carried out. The probability density function for a normal distribution with a mean of 0 and a standard deviation of 1 is given by the following equation:

$$
f(z)=\frac{1}{\sqrt{2 \pi}} \mathrm{e}^{-\frac{z^{2}}{2}}
$$

(Pohlert, 2020)

The Seasonal Kendall (SK) test for trend was developed by the U.S. Geological Survey (Helsel et al., 2005) and has become the most frequently used test for trend in the environmental sciences. Recently the test was modified to form the Regional Kendall (RK) test for trend. The program also provides a means for computing the RK test and the simpler Mann-Kendall test for trend.

In fact, the number of database of Vietnam's island system is not large, often sporadic and lack of synchronization between islands. Therefore, to perform this study, the authors conducted some field trips and collected data from the People's Committees of the two island districts. Then, Mann-Kendall model was applied to estimate the trend of some socio-economic elements in Ly Son and Phu Quy island districts. The results will be presented in Part 4.

\section{Results and Discussion}

\subsection{Trend of Development in Small Island Districts in Tropical Monsoon Region}

To assess the development trend of small islands in the tropical monsoon region, this study will focus on the main economic sectors including fishing, tourism and agriculture. On the other hand, due to small sizes of the islands and high population density, the increase in population will also affect the sustainable development of the islands. Thus, the assessment of increasing population trend will also be considered in this study. Calculated results of Mann-Kendall model are presented in Tables 1-3. 
Table 1. Results of application of the Mann-Kendall model for population and labor.

\begin{tabular}{|c|c|c|}
\hline Element & Ly Son & Phu Quy \\
\hline \multicolumn{3}{|c|}{ Population } \\
\hline Tau & 0.993 & 1.000 \\
\hline$S$ & 135.000 & 91 \\
\hline$z$ & 5.525 & 4.927 \\
\hline$p$ & 0.000 & 0.000 \\
\hline $\mathrm{y}$ & $180.2 \times X-0.34099 \mathrm{E}+06$ & $361.8 \times X-0.70123 \mathrm{E}+06$ \\
\hline \multicolumn{3}{|c|}{ Labor in all sectors } \\
\hline Tau & 1.000 & 1.000 \\
\hline$S$ & 36.000 & 21.000 \\
\hline$z$ & 3.649 & 3.004 \\
\hline$p$ & 0.0003 & 0.0027 \\
\hline y & $61.88 \times X-0.11098 \mathrm{E}+06$ & $629.8 \times X-0.12518 \mathrm{E}+07$ \\
\hline
\end{tabular}

Where: Tau: Kendall's tau statistic; $p$-value: two-sided $p$-value; Score: Kendall Score (S); Denominator: denominator $(D)$, such that tau $=S / D$; $\operatorname{Var}$ (Score): variance of Kendall Score.

Table 2. Results of applying the Mann-Kendall model for gross output of agriculture, fishing and industry sectors.

\begin{tabular}{|c|c|c|}
\hline Element & Ly Son & Phu Quy \\
\hline \multicolumn{3}{|c|}{ Agriculture } \\
\hline Tau & 0.389 & 0.879 \\
\hline$S$ & 14.000 & 58.000 \\
\hline$z$ & 1.355 & 3.900 \\
\hline$p$ & 0.1753 & 0.0001 \\
\hline$y$ & $3.196 \times X-6345$ & $6435 \times X-0.12917 \mathrm{E}+08$ \\
\hline \multicolumn{3}{|c|}{ Fishing } \\
\hline Tau & 0.167 & 1.000 \\
\hline$S$ & 6.000 & 55.000 \\
\hline$z$ & 0.521 & 4.204 \\
\hline$p$ & 0.6002 & 0.000 \\
\hline$y$ & $20.6 \times X-39663$ & $95.73 \times X-0.19203 \mathrm{E}+06$ \\
\hline \multicolumn{3}{|c|}{ Industry } \\
\hline Tau & 1.000 & 1.000 \\
\hline$S$ & 36.000 & 45.000 \\
\hline$z$ & 3.649 & 3.935 \\
\hline$p$ & 0.0003 & 0.0001 \\
\hline$y$ & $14.85 \times X-29849$ & $124.7 \times X-0.25005 \mathrm{E}+6$ \\
\hline
\end{tabular}


Table 3. Results of application of the Mann-Kendall model for tourism sector.

\begin{tabular}{|c|c|c|}
\hline Element & Ly Son & Phu Quy \\
\hline \multicolumn{3}{|c|}{ Visitors } \\
\hline Tau & 0.981 & 0.600 \\
\hline$S$ & 49.000 & 6.000 \\
\hline$z$ & 3.737 & 1.225 \\
\hline$p$ & 0.0002 & 0.2207 \\
\hline$y$ & $0.2237 \mathrm{E}+05 \times X-0.45008 \mathrm{E}+08$ & $2648.0 \times X-0.53254 \mathrm{E}+07$ \\
\hline \multicolumn{3}{|c|}{ Enterprise } \\
\hline Tau & 1.000 & 0.933 \\
\hline$S$ & 36.000 & 42.000 \\
\hline$z$ & 3.649 & 3.722 \\
\hline$p$ & 0.0003 & 0.0002 \\
\hline$y$ & $35.32 \times X-71035$ & $1.25 \times X-2505.4$ \\
\hline \multicolumn{3}{|c|}{ Employment (Hotel, Restaurant) } \\
\hline Tau & 1.000 & 0.978 \\
\hline$S$ & 36.000 & 44.000 \\
\hline$z$ & 3.649 & 3.862 \\
\hline$p$ & 0.0003 & 0.0001 \\
\hline y & $54.0 \times X-0.10845 \mathrm{E}+6$ & $3.000 \times X-6016.5$ \\
\hline
\end{tabular}

According to statistics data (Statistics Office of Ly Son, 2019), the population of Ly Son district in 2018 was 22,086 people in 3 communes. The average population density of the district is 2126 people $/ \mathrm{km}^{2}$. The population densities of each communes in the district is high: An Vinh 2711 people $/ \mathrm{km}^{2}$; An Hai 1,792 people $/ \mathrm{km}^{2}$ and An Binh 704 people $/ \mathrm{km}^{2}$. However, compared with the mainland districts, the population growth rate of Ly Son island district is not large. The average annual population growth rate is less than $1 \%$ (Figure 4). Especially in An Binh commune, the population tends to decrease. In 2018, the district's labor resource was 13,796 people. The labor force in all economic sectors of Ly Son island district increased in the period of 2010-2018 (Figure 5).

According to the statistical yearbook of 2018 (Statistics Office of Phu Quy, 2019), the population of Phu Quy district was 28,308 people in 2018, the average population density was 1581 people $/ \mathrm{km}^{2}$ (Figure 6). In 2016, the population in labor force is 18,095 people. The labor in all economic sectors of Phu Quy island district increased in the period of 2010-2016 (Figure 7). However, this island district's agriculture is only seasonal production, seafood processing industry has not been developed concentratedly. Therefore, the number of unemployed workers in the district is still high, especially female workers. In general, the relative abundance of labor force is a favorable condition for the socio-economic development. However, the labor force with professional and technical qualifications in the district is still low. Therefore, in the future, it is necessary to have a direction for vocational training for workers, especially in science and technology, to meet the labor needs in the condition of ever increasing scientific and technical conditions. 


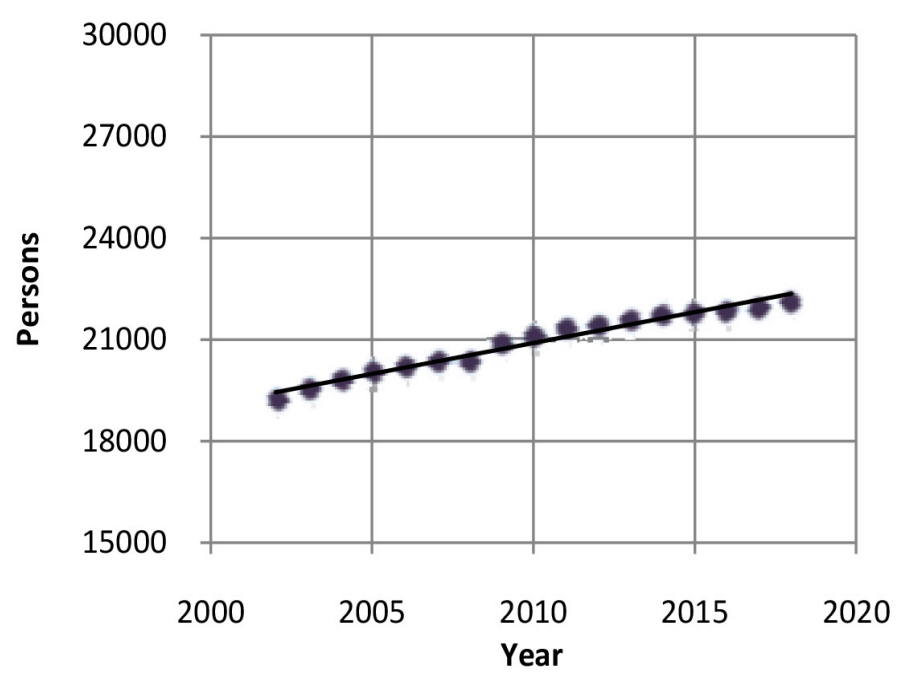

Figure 4. Population of Ly Son island district in the period of 2002-2018.

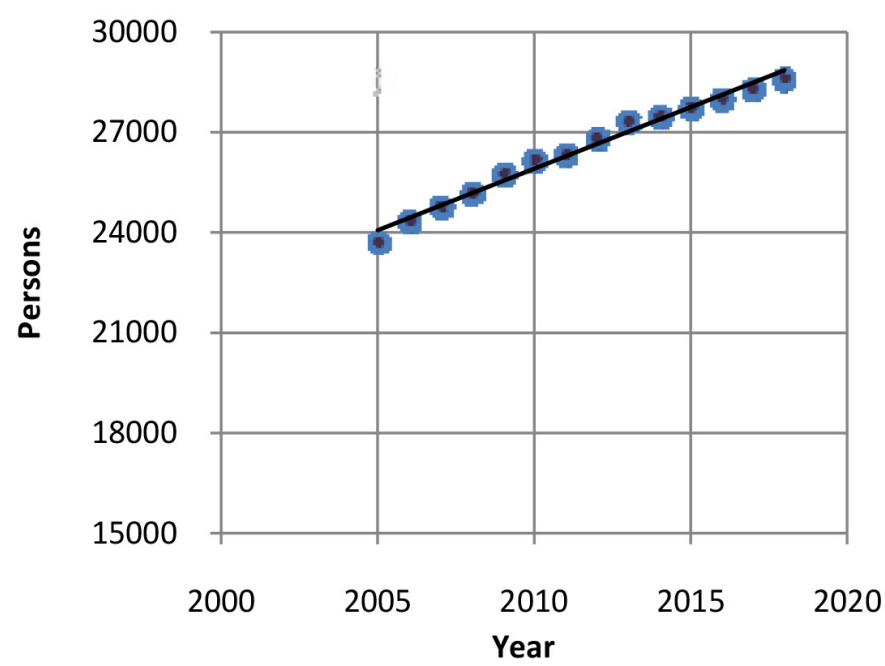

Figure 5. Population of Phu Quy island district in the period of 2005-2018.

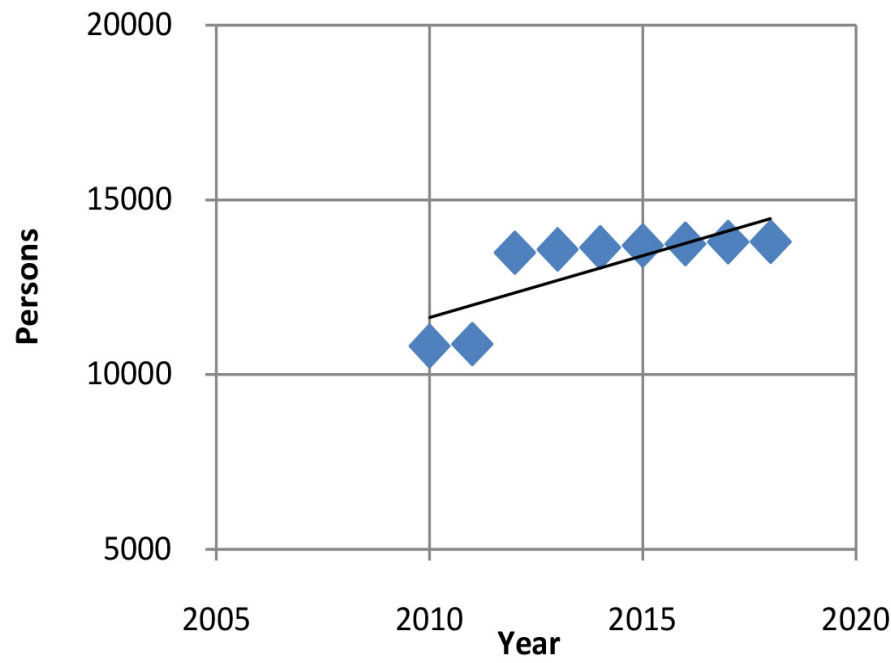

Figure 6. Labor in all economic sectors of Ly Son island district in the period of 2010-2018. 


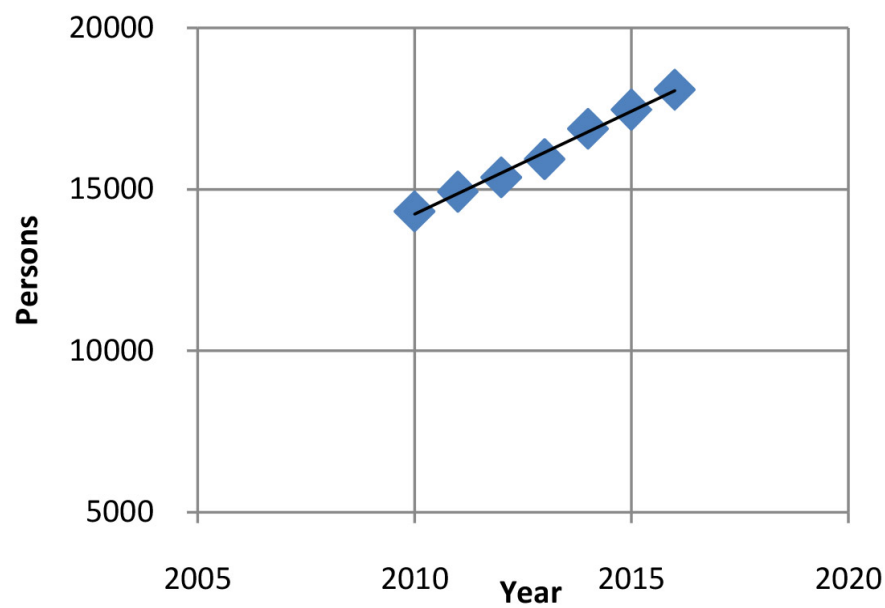

Figure 7. Labor in all economic sectors of Phu Quy island district in the period of 2010-2016.

Ly Son and Phu Quy have quite different economic characteristics but in both districts, the agricultural production value accounts for the lowest proportion, although there is an increasing trend (Figure 8 and Figure 9). More notably, Ly Son has a very famous agricultural product, one-clove garlic, with high economic value. However, as the area of growing garlic is not large, the production value is not high.

The production value of fishing sector accounts for a large proportion in the economic sectors of the two island districts but in fact, the production value of this sector in both island districts has quite complex fluctuation, especially for Ly Son due to its high dependence on nature and fishing grounds as well as market prices. In general, the production value of fishing has been increasing recently (Figure 10 and Figure 11).

Manufacturing, cottage industry and handicrafts industry in the two island districts also have quite different characteristics despite the increasing tendency. The growth rate of industrial production value of Phu Quy island district increases at a faster rate and accounts for a larger proportion of the total value of industries compared to that of Ly Son Island (Figure 12 and Figure 13).

Ly Son is a district with great potential to develop tourism services such as tourist swimming activities, resort tourism, and eco-tourism. In addition, the district has several unique historical sites and folk festivals that can attract tourists to visit and learn. Tourism activities are more developed than before, service facilities, accommodation and motor vehicles are gradually invested, basically meeting the needs of tourists and people. Tourism activities have flourished, the number of tourists coming to Ly Son to visit landscapes, learn and enjoy traditional festivals on holidays, Tet and holidays are on the rise. Ly Son tourism in recent years has developed rapidly. The island welcomed nearly 165,000 visitors in 2016 and 230,320 visitors in 2018. Ly Son district currently has 109 business establishments with nearly 650 rooms. Infrastructure for tourism continues to be invested in construction, service quality is gradually improved. The trend of tourism development is presented in Figures 14-16. 


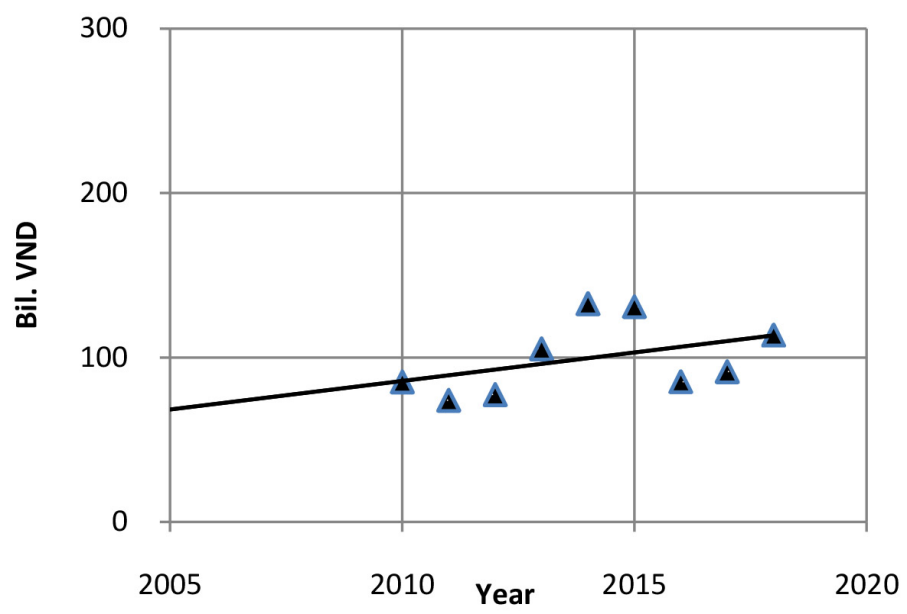

Figure 8. Gross output of agriculture sector of Ly Son island district in the period of 2010-2018.

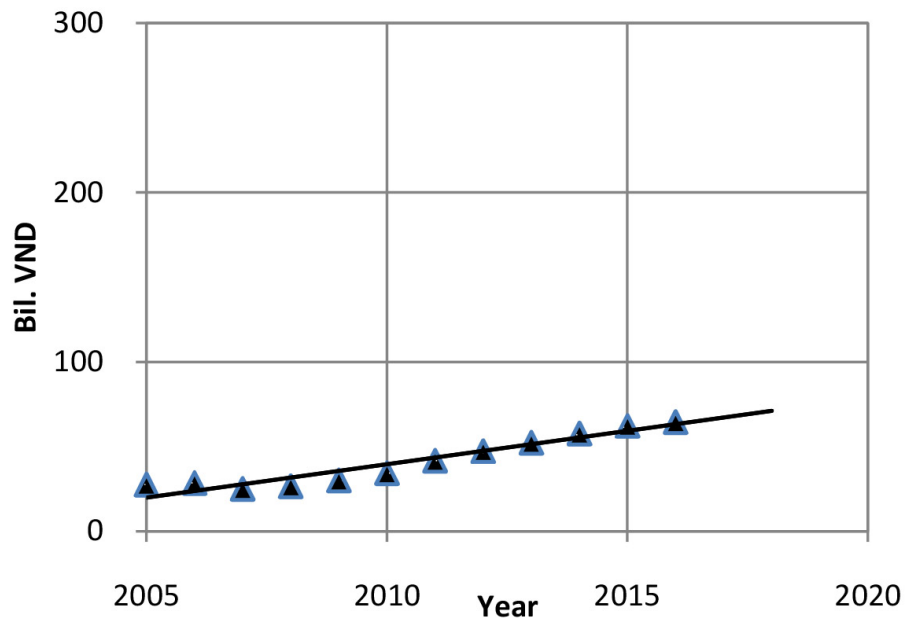

Figure 9. Gross output of agriculture sector of Phu Quy island district in the period of 2005-2016.

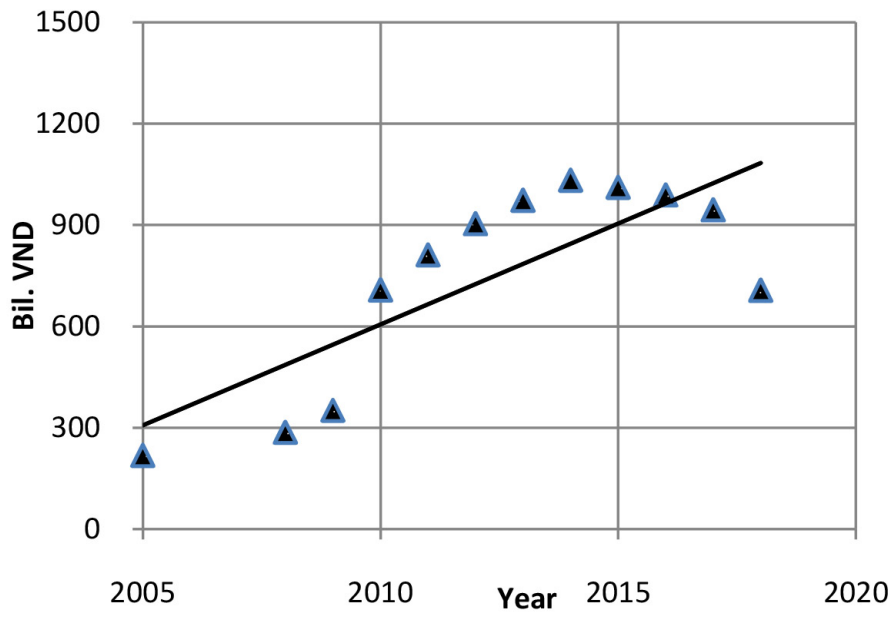

Figure 10. Gross output of fishing sector of Ly Son island district in the period of 2005-2018. 


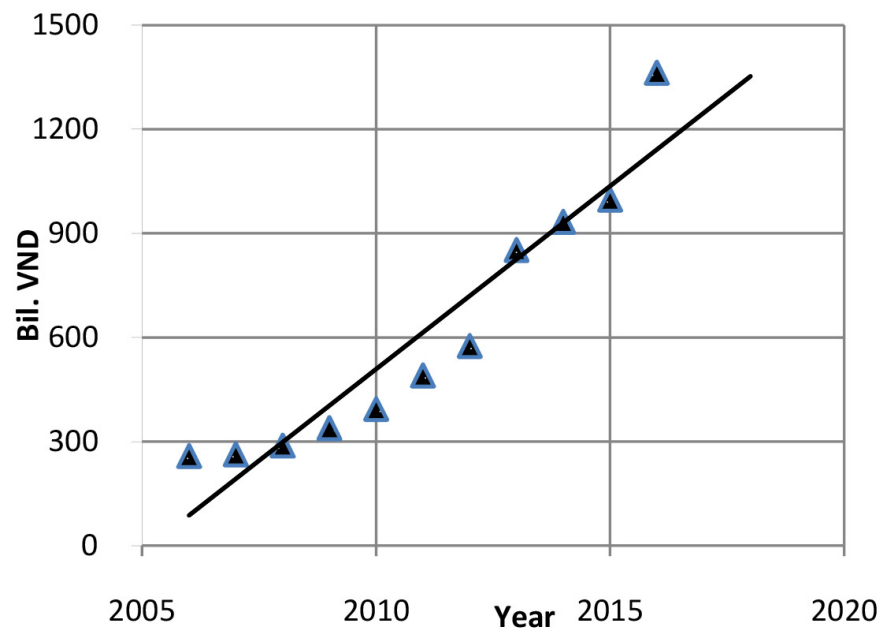

Figure 11. Gross output of fishing sector of Phu Quy island district in the period of 2006-2016.

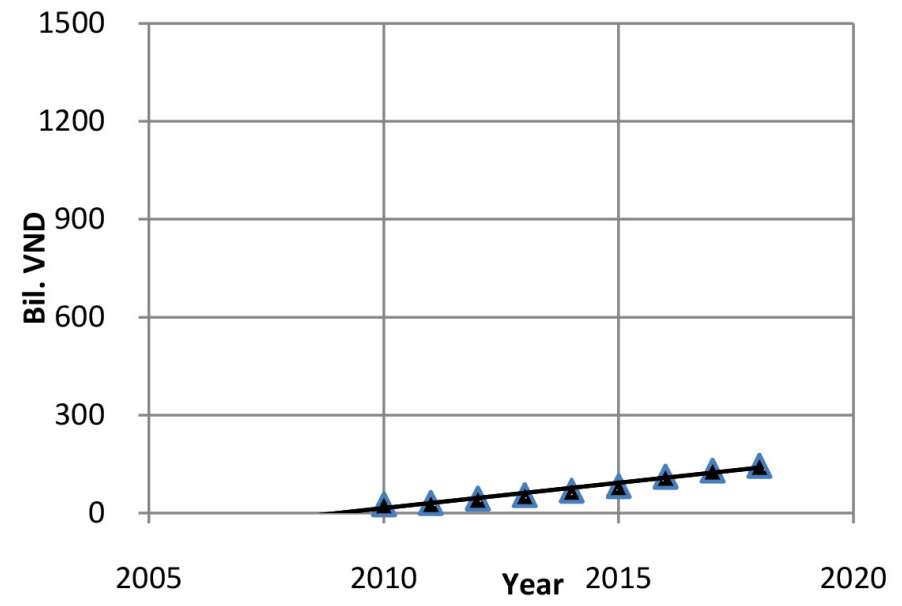

Figure 12. Gross output of industry sector of Ly Son island district in the period of 2010-2018.

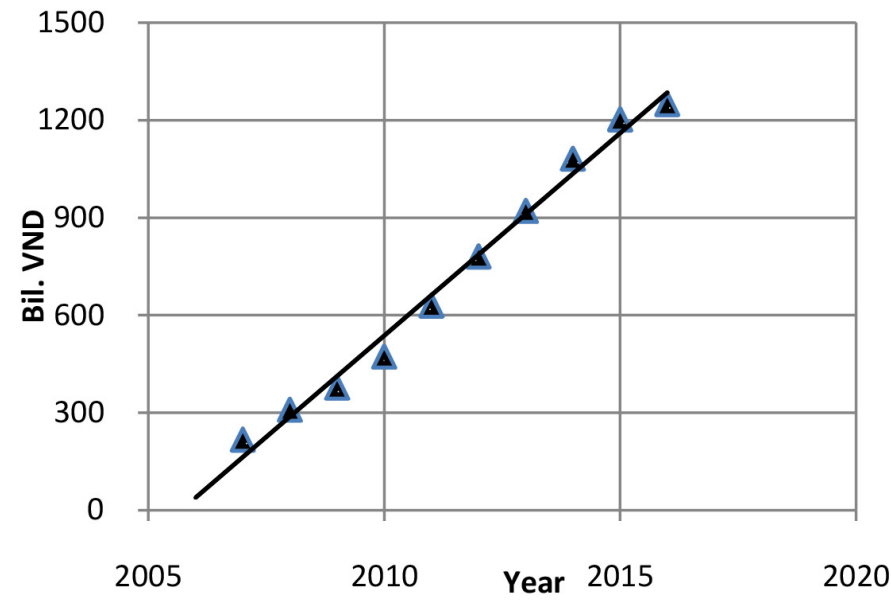

Figure 13. Gross output of industry sector of Phu Quy island district in the period of 2007-2016. 


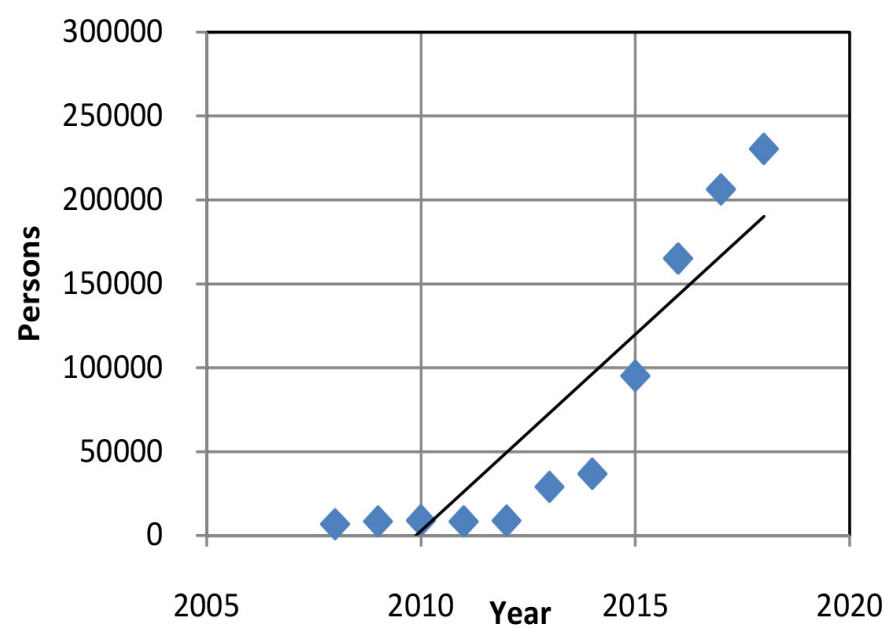

Figure 14. The number of visitors of Ly Son island district in the period of 2008-2018.

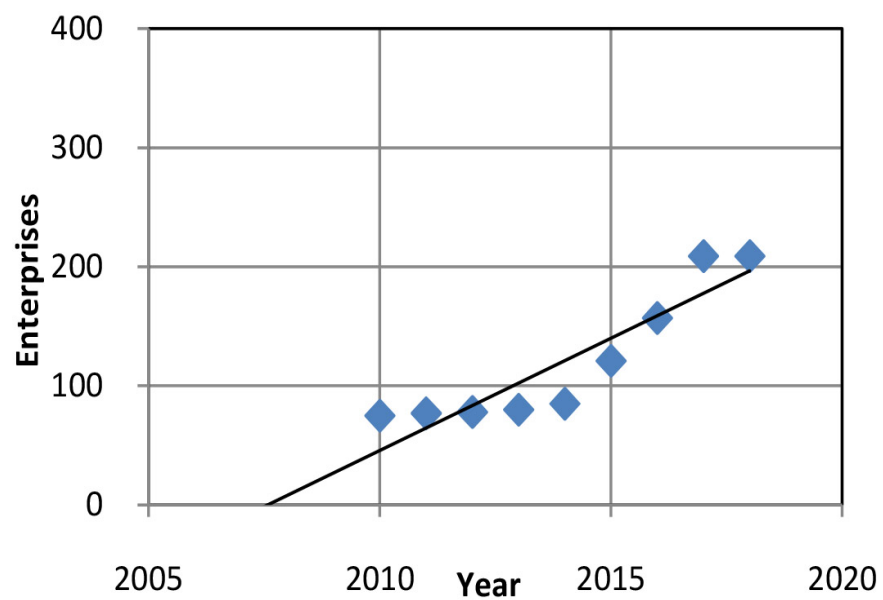

Figure 15. The number of enterprises in the field of Hotel and Restaurant of Ly Son island district in the period of 2010-2018.

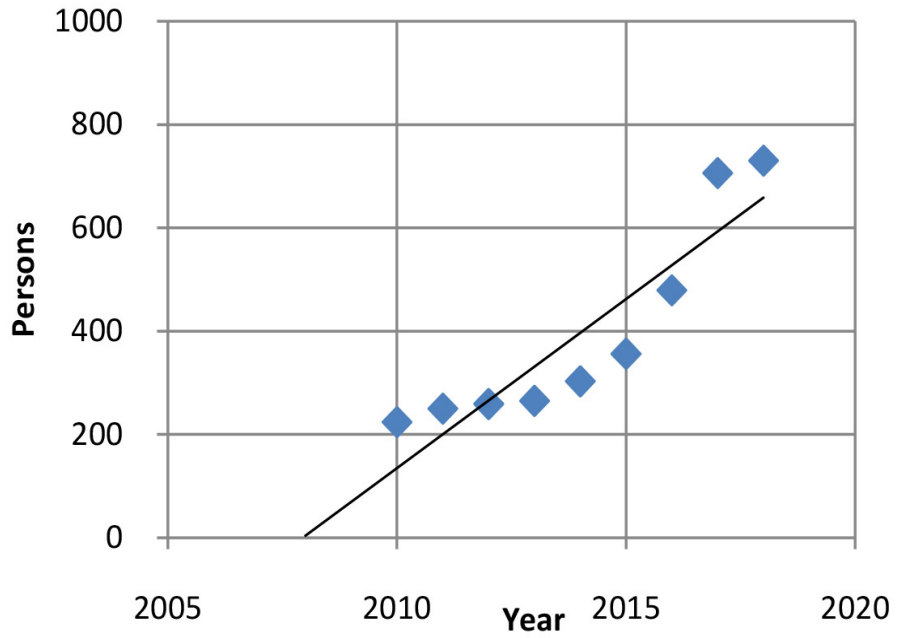

Figure 16. Employment in the field of hotel and restaurant of Ly Son island district in the period of 2010-2018. 
In recent years, the number of tourists to Phu Quy island district has increased rapidly. Trieu Duong Bay area has been renovated and invested into an entertainment and tourism area. However, up to now, according to the actual investigation of the project, the infrastructure for tourism, such as hotel and restaurant, is very limited and not meeting the needs of tourists on public holidays. Tourism development gradually flourishes, with diverse forms of tourism (marine ecotourism, cultural tourism, belief...). The People's Committee of the district has approved the project of constructing Phu Quy tourist area. In 2018, there were about 19,500 visitors. The development trends of visitors, enterprises and employment in the field of hotel and restaurants are presented in Figures 17-19.

Through comparison, tourism development on Ly Son island district is divided into 2 distinct periods, before and after 2015. It is remarkable that the national electricity grid was pulled out on September 28, 2014 for Ly Son. Before that, the source of electricity used by people on the island was diesel power. Especially in 2015, the Sa Ky-Ly Son route and vice versa, being the sea route with the length of 15 miles (33 km), was officially recognized by the Ministry of Transport. In 2017, in addition to 11 inland waterway transports, there were 5 transport companies and 10 wooden ships with a tonnage of $40-80$ tons; all of which were operated to transport goods from the mainland to the island and vice versa, mainly necessities for daily life and construction materials for the island. In the past, the time of transporting by wooden ships was about 2 - 3 hours/time. In 2014, high-speed ships were introduced, significantly shortening the transporting time to $40-60$ minutes/trip. After 5 years, by 2019, high-speed ships gave way to super high-speed ships, making the time to island only 35 minutes/trip. These are favorable conditions to promote tourism development in particular and economic development in general of island districts.

In contrast, Phu Quy island district is $120 \mathrm{~km}$ away from the mainland. Hence, it must use diesel and wind electric power. On 24/01/2013, Phu Quy Wind Power Plant went into operation. This is the first wind power project in Vietnam using a wind-diesel operating model. The plant has a capacity of $6 \mathrm{MW}$, including

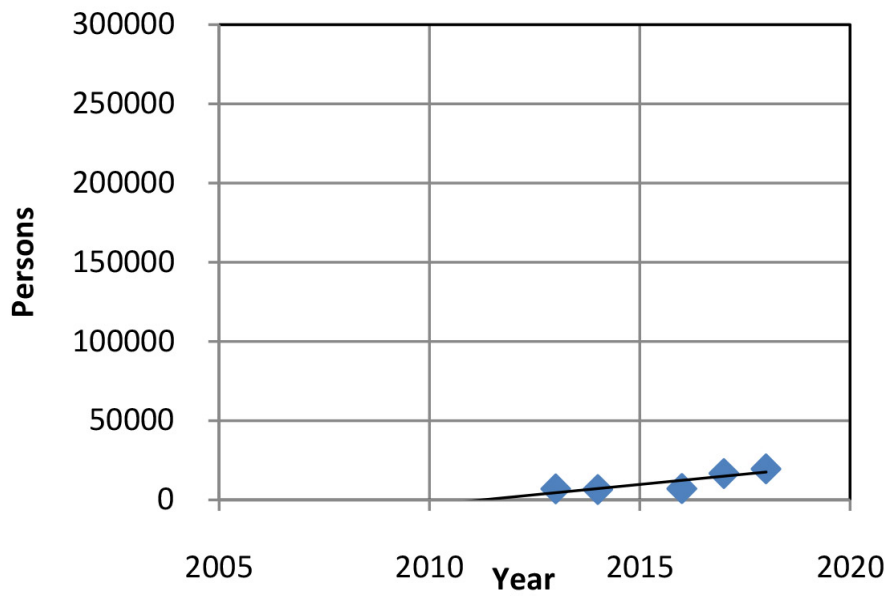

Figure 17. The number of visitors of Phu Quy island district in the period of 2013-2018. 


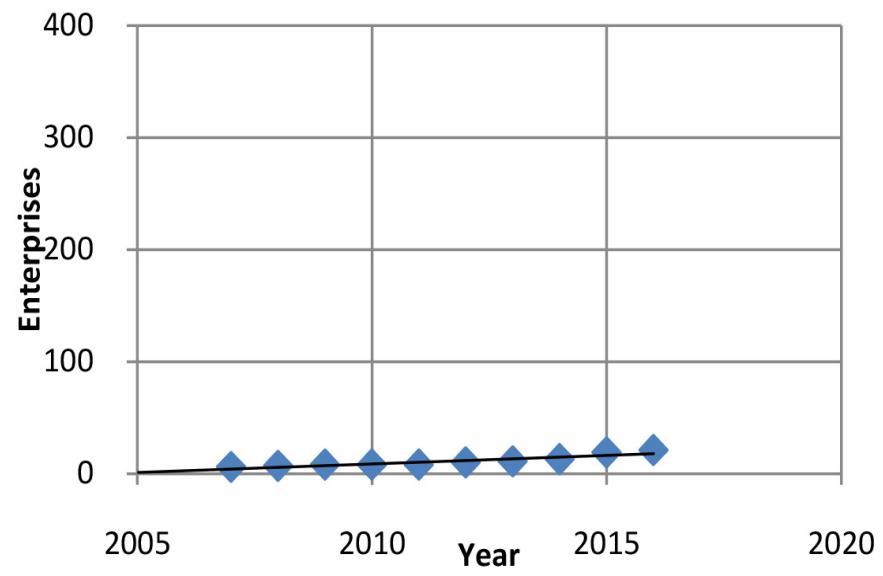

Figure 18. The number of enterprises in the field of hotel and restaurant of Phu Quy island district in the period of 2007-2016.

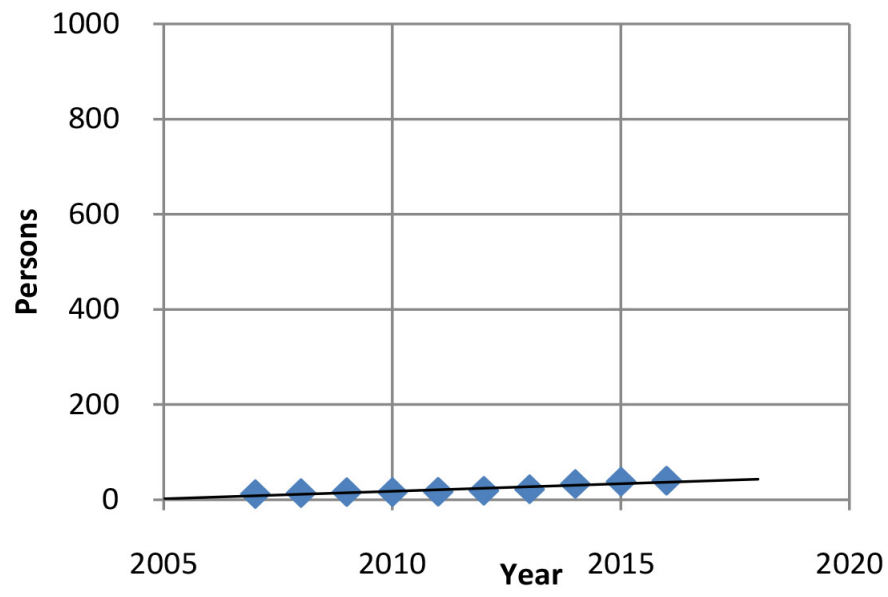

Figure 19. Employment in the field of hotel and restaurant of Phu Quy island district in the period of 2007-2016.

three turbine piers, the height of each turbine tower is $60 \mathrm{~m}$, including three blades, each wing is $37 \mathrm{~m}$ long, and the wind diameter when the fan is $75 \mathrm{~m}$. On the other hand, although there are high-speed trains from Phan Thiet to Phu Quy, the transporting time is still from 2 - 3 hours; the infrastructure conditions on the island have not met and consequently, the number of passengers has increased but not much. As seen in Figures 14-16, Phu Quy did not clearly form 2 economic development phases in comparison to Ly Son.

\subsection{Proposal for Some Solutions to Sustainable Development for Small Islands in Tropical Monsoon Region}

Through the application of the Mann-Kendall model, it is possible to see the increasing trend of most socio-economic factors of the two island districts. Ly Son island district has faster growth rate than that of Phu Quy because Phu Quy is farther from the mainland, more difficult to access and this island district does not own distinct local products. However, with the current development speed, Ly Son is facing several consequences such as insufficient water sources to meet 
the water demand and security instability due to the increasing number of visitors to the island. In order to meet the needs of the development of many tourist service establishments, restaurants, hotels as well as manpower in this industry also increased. If this increase is not controlled, the inherent balance of nature as well as society will be changed. Not only nature but also society will be affected by the overload that human is imposing on it. This is the reason why this study proposes some solutions for sustainable development for island districts in the monsoon tropics:

- Currently, both island districts have already had socio-economic development plans, but the issued plans have become quite old. "The overall planning of socio-economic development of Ly Son district toward 2020" was approved in 2012 and the report of "Planning on socio-economic development of Phu Quy district in the period of 2006-2020" was approved in 2007. In order to match the development trend as well as the context of the area, both island districts need to develop a new plan in addition to the plans of some economic sectors that have been built recently. It is necessary to have a specific structure of economic development orientations according to a phased schedule to ensure sustainable socio-economic development and national security.

- Tourism services in both island districts have prospered, the number of tourists has increased rapidly but it has not been sustainable. In recent years, infrastructure for tourism development in both island districts has been invested but the spontaneous rate is quite large; water resources to meet the needs of both island districts are in difficulty. Ly Son already has typical tourism products but Phu Quy has not yet been determined. Tourism services are few and not yet in high quality, although they have been focused in recent years. Therefore, in order to develop tourism or the economy in general in a sustainable way for both island districts, besides the development of tourism according to the plan, attention should be paid to the environmental capacity issue.

- In recent years, the value of fishery products has decreased and offshore fishing in island districts is at risk. Near-shore fishing still has a situation of using explosives, electric impulses, small meshes, making aquatic resources decline. Therefore, to promote fisheries development as strength of island districts, fishing methods and equipment should properly be considered.

- With favorable nature, the two island districts can fully promote economic development in the direction of tourism service. However, both island districts are currently coping with the indiscriminate waste as well as sewage disposal on the road. To solve this situation, it is necessary to arrange more trash bins along the roads, organize a timely collection and replace special damaged trash bins. In order to strategically develop tourism, the arrangement of mobile toilets must be done immediately. Propaganda and advocacy to reduce the use of plastic bags should also be implemented. 
As shown in the calculated results, the development speeds of the island districts of Vietnam are at different stages. The development speed of Ly Son island district is faster than that of Phu Quy. However, Ly Son is currently facing many consequences, especially environmental issues (Figure 20). Some pictures of Phu Quy island district are shown in Figure 21. Therefore, in addition to common

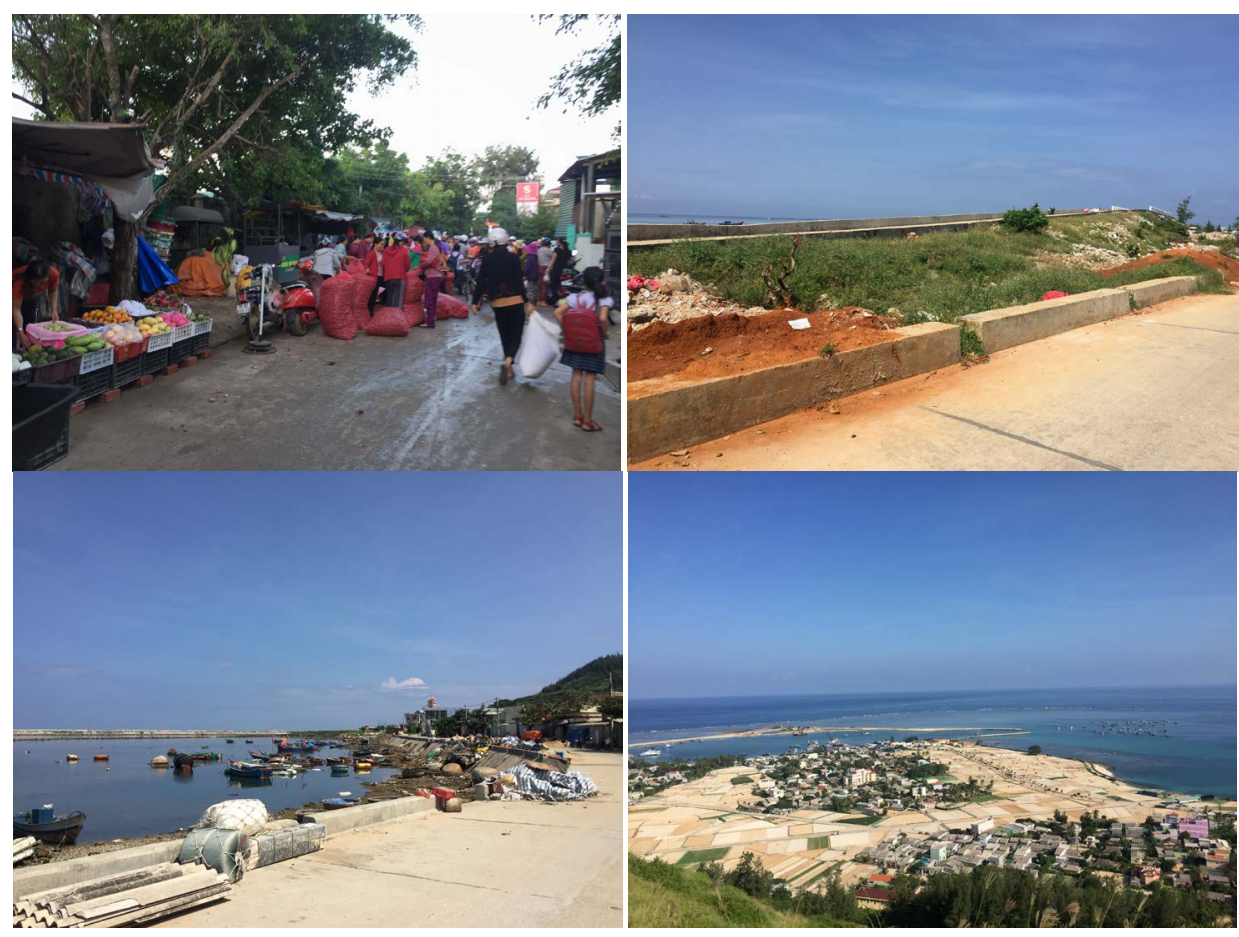

Figure 20. Some pictures of Ly Son island district.

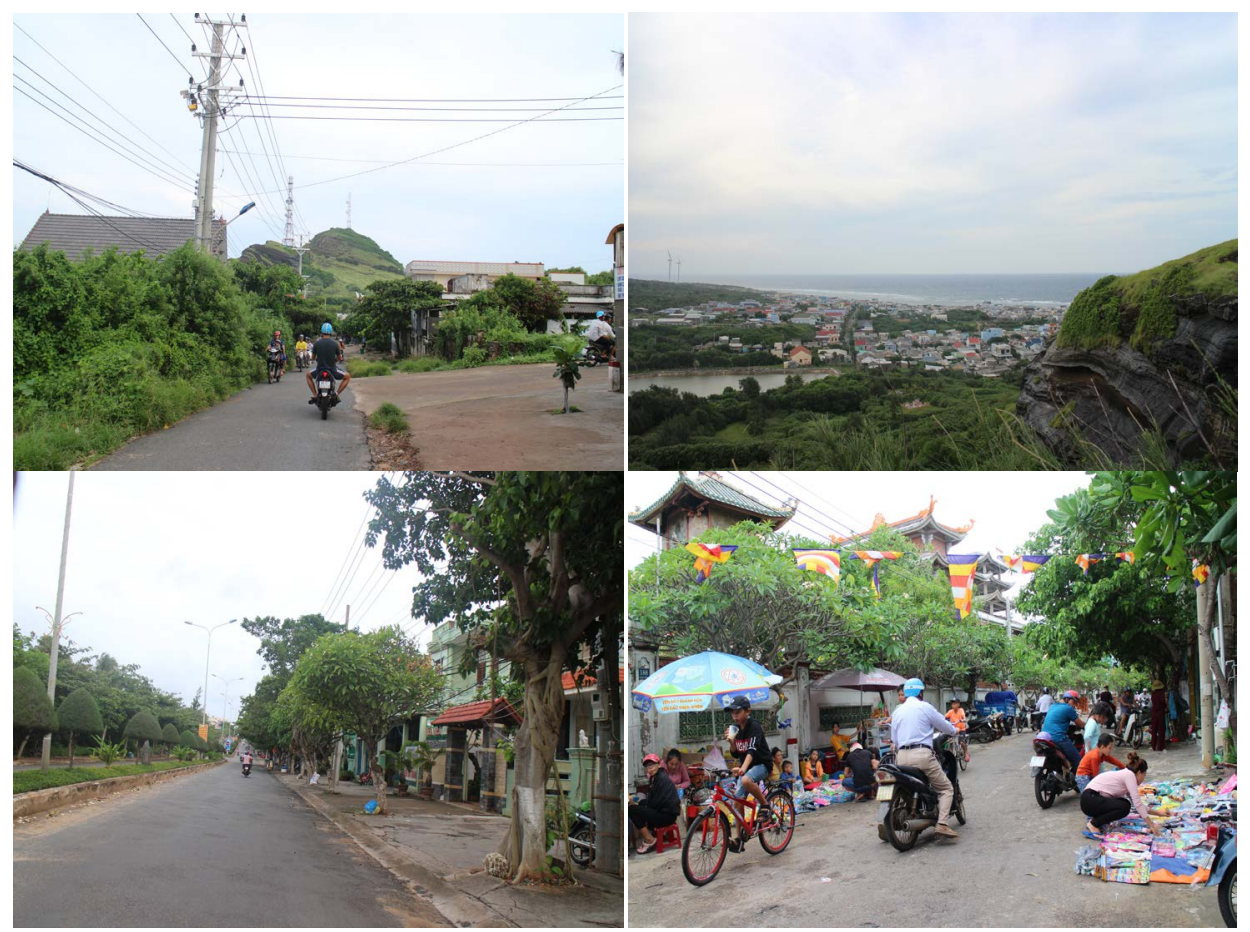

Figure 21. Some pictures of Phu Quy island district. 
solutions for sustainable development, it is high time to put an emphasis on specific solutions for each island district as follows:

- Ly Son: The management of tourism activities and related activities must strictly be implemented. The construction of infrastructure for tourism development must closely follow the planning scheme. In order to avoid the tourist overload that causes negative impacts on the environment, the number of tourists coming to the island must be controlled and limited.

- Phu Quy: While Phu Quy island district is still at the early stage of developing tourism service, it is urgent to immediately build and implement a tourism development plan.

\section{Conclusion}

Ly Son (Quang Ngai province) and Phu Quy (Binh Thuan province) are two island districts in the central region of Vietnam. Sustainable socio-economic development has been identified as an urgent task for island districts. The application results of the Man-Kendall model showed the increasing trend of some socio-economic elements that have been collected. Collecting socio-economic data as well as natural and environmental data for island districts in the monsoon tropics is difficult due to their smallness in size, short and asynchronous number of chains between island districts. These are difficulties to carry out research on island districts. However, this is only a research result with a series of data collected before 2018. By 2020, due to the impact of the Corona virus pandemic, there will certainly be socio-economic fluctuations in dense island districts. The number of tourists visiting the island will unavoidably decrease.

This research also proposed that, in order to sustainably develop the two island districts, there should be a specific structure for economic development orientation among sectors based on the phased schedule. Tourism development planning should pay attention to capacity. On the other hand, fishing should focus on methods and fishing equipment. Infrastructure investment for environmental protection as well as advocacy to minimize the use of plastic bags should be done on a regular basis.

\section{Acknowledgements}

The authors would like to thank anonymous reviewers for their helpful comments. The authors also express their gratitude to Marine Science and Technology Program (KC 09/16-20), the project on "Scientific basic, orientation and solution for sustainable socio-economic development of Ly Son and Phu Quy island districts" (KC.09.37/16-20) and Vietnam Academy of Science and Technology (NCVCC10.07/20-20) in support of this research.

\section{Conflicts of Interest}

The authors declare no conflicts of interest regarding the publication of this paper. 


\section{References}

Banos-Gonzalez, I., Martinez-Fernandez, J., \& Esteve, M. (2016). Tools for Sustainability Assessment in Island Socio-Ecological Systems: An Application to the Canary Islands. Island Studies Journal, 11, 9-34.

Bass, S. M. J. (1993). Ecology and Economics in Small Islands: Constructing a Framework for Sustainable Development. In E. Barbier (Ed.), Economics and Ecology: New Frontiers and Sustainable Development (pp. 156-176). London: Chapman and Hall. https://doi.org/10.1007/978-94-011-1518-6_10

Connell, J. (2018). Islands: Balancing Development and Sustainability? Environmental Conservation, 45, 111-124. https://doi.org/10.1017/S0376892918000036

Department of Economic and Social Affairs, Division for Sustainable Development (2014). Trends in Sustainable Development: Small Island Developing States (SIDS) (37 p.). New York: United Nations.

Helsel, D. R., Mueller, D. K., \& Slack, J. R. (2005). Computer Program for the Kendall Family of Trend Tests. USGS Scientific Investigations Report 2005-5275, Reston, VA: U.S. Geological Survey. http://pubs.usgs.gov/sir/2005/5275 https://doi.org/10.3133/sir20055275

Kendall, M. G. (1975). Rank Correlation Methods (4th ed.). London: Charles Griffin.

Mai, T., \& Smith, C. (2015). Addressing the Threats to Tourism Sustainability Using Systems Thinking: A Case Study of Cat Ba Island, Vietnam. Journal of Sustainable Tourism, 23, 1504-1528. https://doi.org/10.1080/09669582.2015.1045514

MONRE (Ministry of Natural Resources and Environment) (2016). Scenarios of Climate Change and Sea Level Rise of Vietnam.

Phan, T. T. H. et al. (2016a). Ly Son Island's Diverse Landscape.

Phan, T. T. H. et al. (2016b). Phu Quy Island's Diverse Landscape.

Pohlert, T. (2020). Non-Parametric Trend Tests and Change-Point Detection. https://cran.r-project.org/web/packages/trend/vignettes/trend.pdf

Statistics Office of Ly Son (2019). Statistical Yearbook of Ly Son 2018.

Statistics Office of Phu Quy (2019). Statistical Yearbook of Phu Quy 2018. 